Remerciements à l'ensemble des intervenants, des animateurs, des participants et toutes les équipes qui se sont impliquées dans cette nouvelle édition du média-workshop (Paul, Clémence, Isabelle,

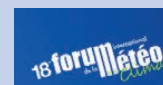

$$
\begin{aligned}
& \text { MEDIA WORKSHOP } \\
& \text { INTERNATIONAL COMMUNICATION ON CLIMATE CHANGE 17-18 JUNE } 2021
\end{aligned}
$$

\#FIMC2021

THANKS TO OUR PARTNERS - MERCI À NOS PARTENAIRES

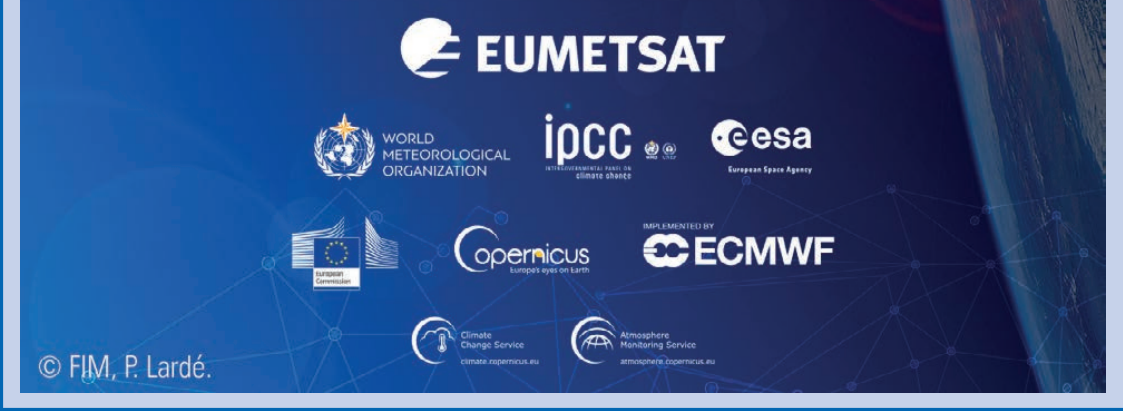

Les replays du média-workshop sont disponibles sur le site du forum : https://forumeteoclimat.com/ programme/media-workshop-2021/ media-workshop-2021-replays/

\section{Morgane Daudier} Météo et Climat

Christian Vannier et Irina Bouzoulouk

Forum international de la météo et du climat

\title{
Prix Perrin de Brichambaut 2021
}

e Prix Perrin de Brichambaut a été créé en 1997 pour récompenser une classe ayant réalisé un projet dans le domaine de la météorologie, du climat ou de l'environnement.

En 2021, le jury s'est réuni sous la présidence de Guy Blanchet le 8 juin au siège de Météo et Climat, à SaintMandé (Val-de-Marne) ; il a examiné 12 dossiers venus de toute la France.

Pour le premier prix (700 euros), le choix s'est fixé sur le travail d'une classe de seconde à projet mondial ODD (Objectif développement durable) du lycée général et technologique de l'Albanais, à Rumilly (Haute-Savoie), accompagnée d'écodélégués de ce lycée. Le dossier est intitulé « Agir pour demain. Lutter et s'adapter au réchauffement climatique »; outre un document de présentation de six pages, le projet comporte neuf vidéos de 2 à 5 minutes traitant de divers problèmes, par exemple la sensibilisation des élèves et de la population au problème du réchauffement, la réduction des émissions de $\mathrm{CO}_{2}$, le tri des vêtements, la surconsommation de viande, la préservation de l'eau potable, etc. Les élèves du lycée ont organisé des ateliers dont les thèmes sont variés (remise en état d'une mare pour étudier la biodiversité,

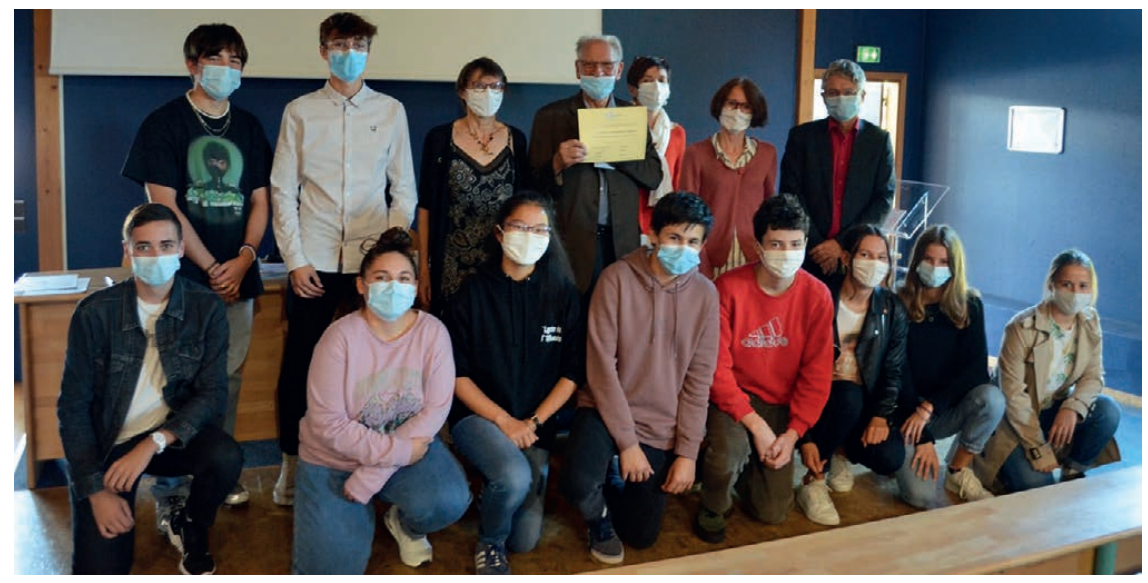

La classe de seconde ODD du lycée de l'Albanais, à Rumilly (Haut-Savoie), est récompensée.

tri des déchets, utilisation d'une imprimante $3 \mathrm{D}$, installation d'une ruche, fabrication de produits cosmétiques, etc.) et coordonnés par un conseil de vie lycéenne.

La remise du prix a eu lieu le 24 septembre au lycée, lors d'un Forum dédié au développement durable, en présence de Bernard Perradin, proviseur, de Myriam Amet, professeur de SVT responsable du projet, de Manon Boukili, adjointe au maire de Rumilly, de Valérie Caroff, professeur d'histoire et de géographie, de Marie-Sylvie Wattellier, professeur de mathématiques, de
Caroline Dominiconi, professeur de français et d'Emmanuelle Lampin, chargée de mission Développement durable et de nombreux élèves.

Les $2^{\mathrm{e}}$ et $3^{\mathrm{e}}$ prix (500 et 300 euros) ont été décernés respectivement au collège Pierre-et-Marie-Curie de PontAudemer (Eure) pour un dossier intitulé « Tous au courant » et à la cité scolaire Paul-Valéry, à Paris, pour un travail sur « Les risques liés aux catastrophes naturelles ».

\section{Guy Blanchet} Météo et Climat 